\title{
HERMITE NUMERICAL METHOD TO ESTIMATE THE RADON AND RADIUM EFFECTS OF THE SOIL IN BARTELLA REGION
}

\author{
Hekmat SH. Mustafa \\ Department of Mathematics ${ }^{1}$ \\ heksha.math@gmail.com \\ Malik H. Kheder \\ Department of Physics ${ }^{1}$ \\ malik.19732013@yahoo.com \\ Sarah Ghanim Mahmood \\ Department of Mathematics ${ }^{1}$ \\ sarahghanim1989@yahoo.com \\ ${ }^{1}$ Education College \\ University of AL-Hamdaniya \\ Erbil road, Al-Hamdaniya District, Nineveh, Iraq, 41006
}

\begin{abstract}
The Hermite numerical interpolation method used to estimate and predict the radon and radium concentrations, from some of the experimental measurements made on the soil samples of the Bartella region in Iraq. The results obtained from deductible mathematical method were close to real experimental results. Predicted results are in the range of $80.04-4051.59 \mathrm{~Bq} / \mathrm{m}^{3} \mathrm{radon}$ concentrations and $0.322-17.276 \mathrm{~Bq} / \mathrm{Kg}$ radium concentrations corresponding to 200-10000 tracks of alpha particles. The maximum errors were less than 0.289 and 1.172 percent for radon and radium concentrations, respectively. The effects of radium and radon radiations estimated of soil in the studied area depend on its concentrations, a higher number of alpha particle tracks mean high radiation concentration, the high radiation will cause human health damage. The values are below $370 \mathrm{~Bq} / \mathrm{Kg}$ the recommended radium concentration permissible values, by the Organization ащк Economic Cooperation and Development (OECD), the studied area is safe from hazards on health of radium and radon exposure from the soil.

Keywords: concentrations of radon, concentrations of radium, Hermite method, soil samples, applied mathematics, numerical interpolation.
\end{abstract}

DOI: $10.21303 / 2461-4262.2020 .001173$

\section{Introduction}

Applied mathematics is one of the important mathematics branches, it solves applied sciences different problems, it deals with all the stages for solving the problems, namely, given a problem, formulate a mathematical model that describes it, through analytical or numerical methods, solve the model, compare the model results with experimental results, in the case that they disagree qualitatively, go back and reformulate the problem [1]. The numerical Hermite interpolation method used in applied mathematics, which gives values with small amount error from the real values. The method can be used to estimate and predict results close to the experiments from a few sample values when measurements completely are not available for any reason [2]. The Hermite interpolation numerical method is an interpolating method of data points as a function of polynomial. The Hermite interpolating generated polynomial is related closely to the polynomial of Newton, both from the calculation of divided are derived [3]. Hermite approximations method can be generated from the basis of Newton interpolatory formula of divided difference at $x_{0}, x_{1}, \ldots, x_{n}$, that is:

$$
P_{n}(x)=f\left(x_{0}\right)+\sum_{k=1}^{n} f\left[x_{0}, x_{1}, \ldots, x_{k}\right]\left(x-x_{0}\right)\left(x-x_{1}\right) \ldots\left(x-x_{k-1}\right) .
$$


The method uses connection between the $n^{\text {th }}$ derivative of function and the $n^{\text {th }}$ divided difference [4]. The entries used for the first three columns of divided-difference in determining the Hermite polynomial $H_{11}(x)$ for $x_{0}, x_{1}, \ldots, x_{5}$, are shown in the following Table 1.

Table 1

The Newton's divided difference

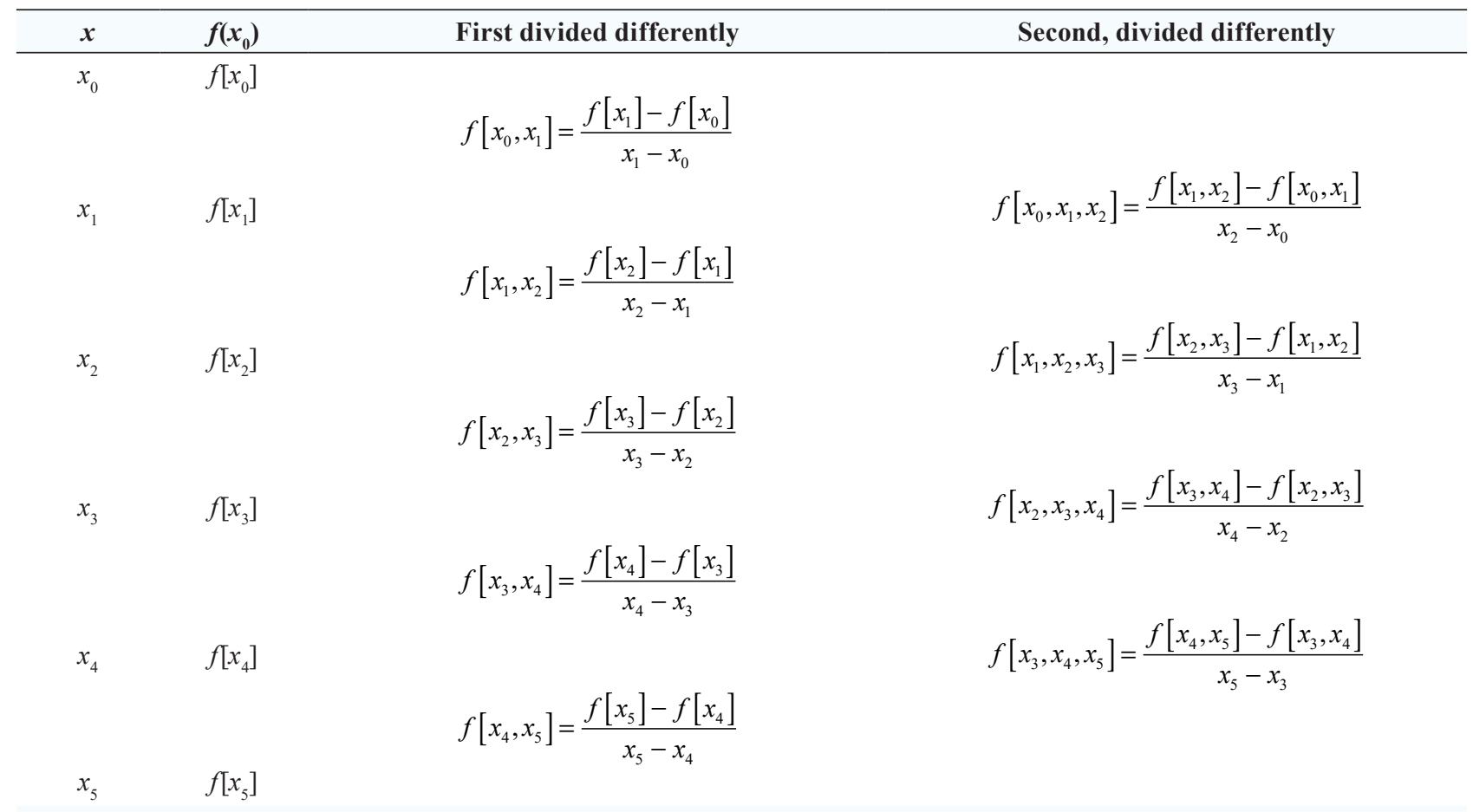

In the same manner the remaining entries generated as that of Newton's divided difference Table 1, the Hermite polynomial is given by [5]:

$$
H_{2 n+1}(x)=f\left[x_{0}\right]+\sum_{k=1}^{2 n+1} f\left[x_{0}, x_{1}, \ldots, x_{k}\right]\left(x-x_{0}\right)\left(x-x_{1}\right) \ldots\left(x-x_{k-1}\right) \text {. }
$$

Recently, many researcher have been studied the estimation subject as, the finite element method (FEM) which is an efficient method for solving the engineering and mathematical physics most diverse problems [6]. The absorbed dose estimation of surface skin for the standard radiological examinations of the patient [7]. Estimation solar radiation diffuse over Iraq [8]. Estimation the concentration of the atmospheric $\mathrm{CO}_{2}$ in Iraq [9]. Estimation soil erosion by the neural network models [10]. Method for time series prediction by small sets of experimental samples [11]. Estimation the air Kerma of entrance surface and dose area product for the examined patient by the long term X-ray examination [12]. Mathematical estimation of the inserted sand column bearing capacity in soft clay soil [13]. Estimation of the soil samples radiological hazardous effects in Nineveh province [14], and others applications [15-17].

In this research, Hermite numerical interpolation method used to obtain a mathematical model for estimatting the radon and radium radiations concentrations amounts, and the effects of the soil of Bartella region, the estimations and measurements were very close together since the very small deviation between them. Radon gas and radium are radioactive elements produced from the decay of well known unstable uranium material element, the decay of radioactive elements occurs with emitting alpha particles, beta particles, or electromagnetic radiations. The effects of these radioactive elements when entries to the human body cause many diseases, an important one is cancers especially lung cancer by the radon. So measurement and control of their concentrations are very important. 


\section{Materials and Methods}

The Hermite method used to estimate the radiation concentrations in the soil samples of Bartella region located in the Nineveh plain region of Iraq, which its an open plain area, mostly has red soils, where $\mathrm{N}$ denotes the radiation emitted alpha particle track counts recorded by a CR-39 nuclear track detector used in measurements the soil sample in the studied area, $R_{k}$ is the radiation concentration, experimental results taken from [18]. The method can be explained as follows:

For the radon element if there are some values of the sample's track count with their corresponding concentration listed in Table 2.

\section{Table 2}

Initial experimental track count with their radon concentrations

\begin{tabular}{ccccc}
\hline & Tracks count $\boldsymbol{N}$ & & \multicolumn{2}{c}{ Concentrations $\boldsymbol{f}(\boldsymbol{N})$} \\
\hline$N_{0}$ & 800 & $f\left(N_{0}\right)$ & 323.2 \\
$N_{1}$ & 933 & $f\left(N_{1}\right)$ & 377.1 \\
$N_{2}$ & 1040 & $f\left(N_{2}\right)$ & 420.2 \\
$N_{3}$ & 1200 & $f\left(N_{3}\right)$ & 484.8
\end{tabular}

As in (2) and Table 1, Hermite polynomial of this situation will be

$$
\begin{gathered}
R_{k}=f\left(N_{0}\right)+f\left[N_{0}, N_{1}\right]\left(N-N_{0}\right)+f\left[N_{0}, N_{1}, N_{2}\right]\left(N-N_{0}\right)\left(N-N_{1}\right)+ \\
+f\left[N_{0}, N_{1}, N_{2}, N_{3}\right]\left(N-N_{0}\right)\left(N-N_{1}\right)\left(N-N_{2}\right) .
\end{gathered}
$$

Substituting the given experimental values for radon from Table 2 into (3) let's obtain

$$
R_{k}=0.40526 N-1.008 \text {. }
$$

This equation by substituting $\mathrm{N}$ estimated the results of radon concentrations.

For the radium element, some values of the sample's track count with their corresponding concentration listed in Table 3.

Table 3

Initial experimental track count with their radium concentrations

\begin{tabular}{ccccc}
\hline & Tracks count $\boldsymbol{N}$ & \multicolumn{2}{c}{ Concentrations $\boldsymbol{f}(\boldsymbol{N})$} \\
\hline$N_{0}$ & 800 & $f\left(N_{0}\right)$ & 1.3 \\
$N_{1}$ & 933 & $f\left(N_{1}\right)$ & 1.59 \\
$N_{2}$ & 1040 & $f\left(N_{2}\right)$ & 1.77 \\
$N_{3}$ & 1200 & $f\left(N_{3}\right)$ & 2.04
\end{tabular}

As in (3) with Substituting the given experimental values for radium from Table 3, let's obtain

$$
R_{k}=0.00173 N-0.024 \text {. }
$$

By substituting $N$ estimated the results of radium concentrations.

\section{Results}

The estimated (predicted) results listed in the Table 4, and the comparison between estimated and experimental results listed in Table $\mathbf{5}$.

The estimated results of radon and radium concentrations from the mathematical method depend on $N$, which represent the number of alpha particle tracks, the range of $N$ is between 200-10000 track as in Table 4. 
Comparison between estimated results and experimental available range of $\mathrm{N}$ between $800-$ 6000 were made, and the percentage deviation form experimental results calculated, the obtained results showed that the calculated results for radon and radium concentrations are accurate and close to experiments since the deviation values are very small, as in Table $\mathbf{5}$.

Table 4

Estimated results of radon and radium obtained from mathematical method

\begin{tabular}{ccc}
\hline $\boldsymbol{N}$ & Radon $\boldsymbol{R}_{\boldsymbol{k}}$ Est. & Radium $\boldsymbol{R}_{\boldsymbol{k}}$ Est. \\
\hline 200 & 80.04 & 0.322 \\
400 & 161.09 & 0.668 \\
600 & 242.14 & 1.014 \\
800 & 323.2 & 1.36 \\
1200 & 485.3 & 2.05 \\
1600 & 647.41 & 2.74 \\
2400 & 971.62 & 4.1 \\
3600 & 1458 & 6.2 \\
3906 & 1582 & 6.73 \\
5066 & 2052 & 8.74 \\
6000 & 2431 & 10.36 \\
7000 & 2835.81 & 12.086 \\
8000 & 3241.07 & 13.816 \\
9000 & 3646.33 & 15.546 \\
10000 & 4051.59 & 17.276
\end{tabular}

Table 5

Comparison between the obtained estimated and available experimental results for radon and radium

\begin{tabular}{|c|c|c|c|c|c|c|}
\hline \multirow[b]{2}{*}{$N$} & \multicolumn{5}{|c|}{ Radon } & Radium \\
\hline & Radon $R_{k}$ Est. & $\operatorname{Radon} R_{k} \operatorname{Exp}$ & $\begin{array}{c}\left|R_{k E s t .}-R_{k E x p}\right| / R_{k E x p} \\
\times \mathbf{1 0 0} \%\end{array}$ & Radium $R_{k}$ Est. & Radium $R_{k}$ Exp. & $\begin{array}{c}\left|R_{k \text { Est. }}-R_{k E x p}\right| / R_{k E x p} \\
\times \mathbf{1 0 0} \%\end{array}$ \\
\hline 800 & 323.2 & 323.2 & 0 & 1.36 & 1.36 & 0 \\
\hline 933 & 377.1 & 377.1 & 0 & 1.59 & 1.59 & 0 \\
\hline 1040 & 420.46 & 420.2 & 0.062 & 1.77 & 1.77 & 0 \\
\hline 1200 & 485.3 & 484.8 & 0.103 & 2.05 & 2.04 & 0.49 \\
\hline 1280 & 517.7 & 517.1 & 0.116 & 2.19 & 2.18 & 0.459 \\
\hline 1600 & 647.41 & 646.4 & 0.156 & 2.74 & 2.73 & 0.366 \\
\hline 1733 & 701.31 & 700.3 & 0.144 & 2.97 & 2.96 & 0.338 \\
\hline 2093 & 847.2 & 845.7 & 0.177 & 3.6 & 3.57 & 0.84 \\
\hline 2266 & 917.3 & 915.8 & 0.164 & 3.9 & 3.87 & 0.775 \\
\hline 2400 & 971.62 & 969.7 & 0.198 & 4.1 & 4.1 & 0 \\
\hline 2933 & 1187.6 & 1185 & 0.221 & 5 & 5 & 0 \\
\hline 3240 & 1312 & 1309 & 0.229 & 5.58 & 5.53 & 0.904 \\
\hline 3600 & 1458 & 1454 & 0.275 & 6.2 & 6.14 & 0.977 \\
\hline 3906 & 1582 & 1578 & 0.253 & 6.73 & 6.67 & 0.9 \\
\hline 4133 & 1674 & 1670 & 0.24 & 7.13 & 7.05 & 1.135 \\
\hline 4266 & 1728 & 1723 & 0.29 & 7.36 & 7.28 & 1.099 \\
\hline 4520 & 1831 & 1826 & 0.274 & 7.8 & 7.68 & 1.563 \\
\hline 4573 & 1852 & 1847 & 0.271 & 7.89 & 7.81 & 1.024 \\
\hline 5066 & 2052 & 2047 & 0.244 & 8.74 & 8.65 & 1.04 \\
\hline 5466 & 2214 & 2208 & 0.272 & 9.43 & 9.33 & 1.072 \\
\hline 6000 & 2431 & 2424 & 0.289 & 10.36 & 10.24 & 1.172 \\
\hline
\end{tabular}




\section{Discussion}

When the proposed mathematical method applied, perfect and conformed results were obtained, the maximum errors were less than 0.289 and 1.172 percent for radon and radium concentrations, respectively, which means that the estimated results are very close to the results of the experiment. The estimated of radon concentration values are in the range of $80.04-4051.59 \mathrm{~Bq} / \mathrm{m}^{3}$ radon concentrations and $0.322-17.276 \mathrm{~Bq} / \mathrm{Kg}$ radium concentrations corresponding to $200-10000$ tracks of alpha particles, The values are below $370 \mathrm{~Bq} / \mathrm{Kg}$ the recommended radium concentration permissible values of (OECD) [19]. The estimated results limitation is its dependence on the accuracy of available experimental measurements that the calculation built upon. The modification and development can be made by taking the average value of several measurements on the each soil sample to increase the accuracy of estimated results, and using different detectors in measurement and comparing between them.

Fig. 1 represents the estimated and experimental radium concentrations which shown that there are predicted values before and after experimental values in the same line means that the radium increasing with increasing of the number of alpha particle tracks, this figure can be used as the calibration curve between tracks and radium concentration.

Fig. 2 shows the radium concentration values with the rearrangement experimental samples, it's from one sample to another varied due to radium content in the sample location. The Bartella region is an open area around houses, it has a large amount of wind and air causes raised radon gas from the soil to diffusion to air, so the results of the measurements show very low values of radon and radium concentrations. The upper limit results are still within the allowed limit, therefore the area under study is safe for life from natural radiation.

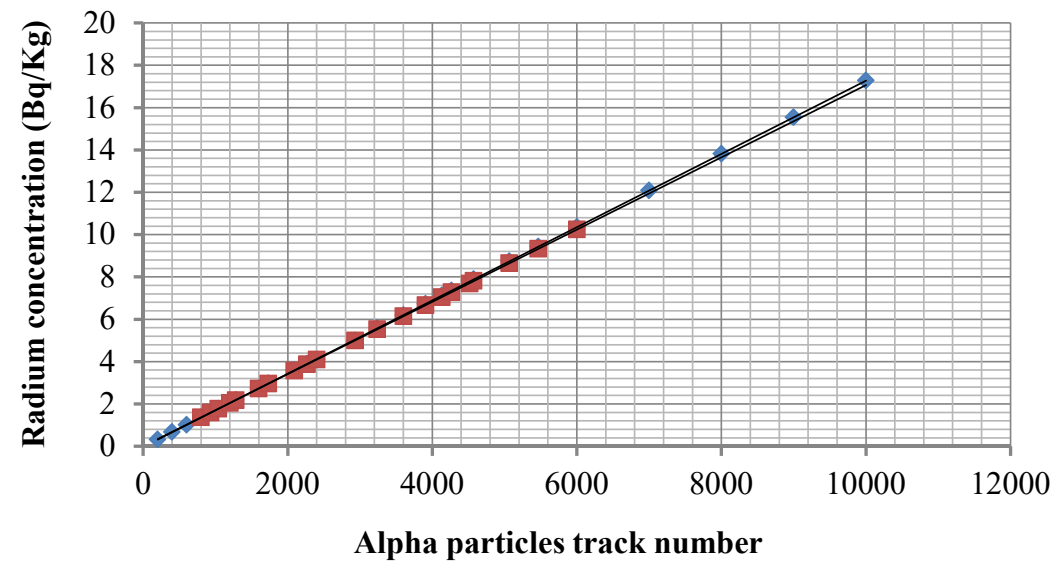

Fig. 1. Radium estimated and experimental concentration variation with alpha track numbers

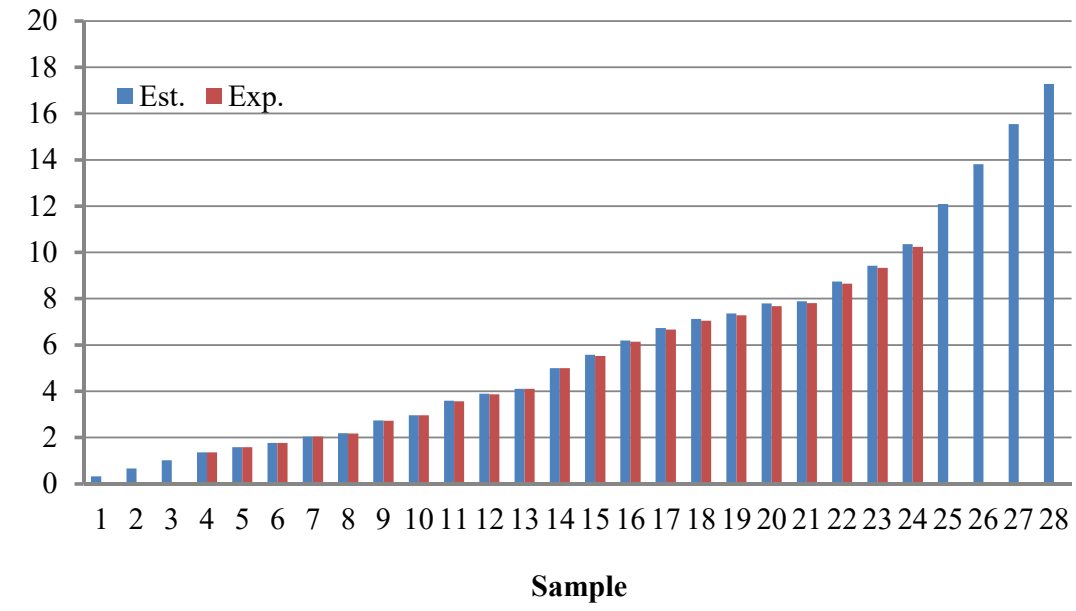

Fig. 2. Radium estimated and experimental concentration variation in the samples 
Fig. 3 shows the obtained good positive correlation between estimated and experimental radium concentrations, it is evident they close together with small amount difference of 1.172 percent between them. This means that using the Hermite interpolation method gives good predicted results.

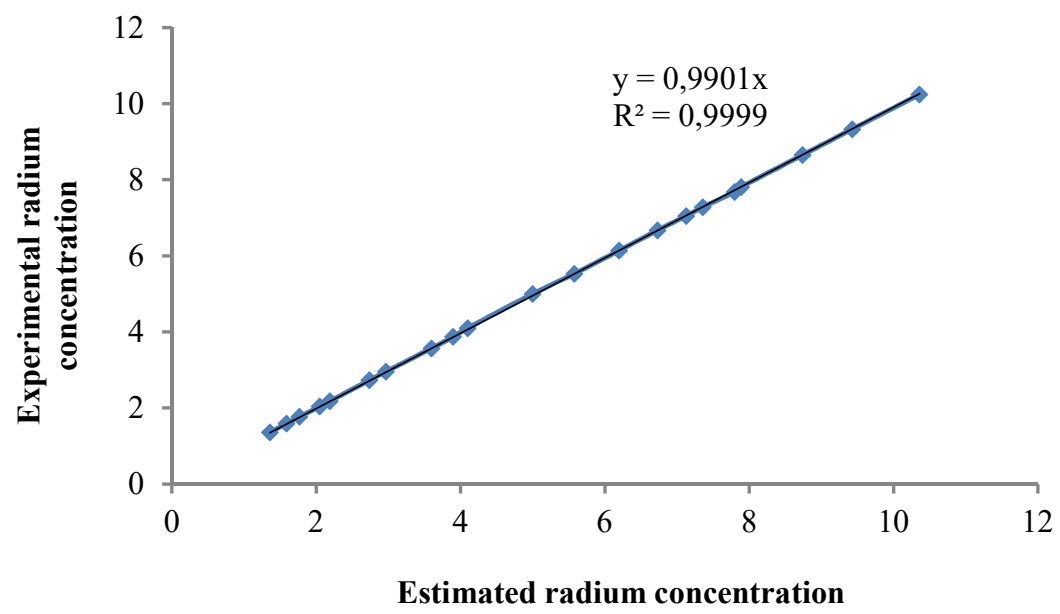

Fig. 3. Radium estimated with experimental concentrations variations.

\section{Conclusions}

In this research, the concentrations of radon and radium in soil samples estimated and predict from some of the experimental measurements, made on the soil samples of the Bartella region.

The higher number of alpha particle tracks means high radiation concentration, the high radiation will cause human health damage.

The values are below $370 \mathrm{~Bq} / \mathrm{Kg}$ the recommended radium concentration permissible values by the Organization for Economic Cooperation and Development (OECD).

A good positive correlation (1.00) has been obtained between the estimated and experimental radium concentration, it is evident they close together with a small amount difference of 1.172 percent between them. This means that using the Hermite interpolation method gives good predicted results.

The Fig. 1 can be used as the calibration curve between number of the tracks and radium concentration.

\section{References}

[1] Logan, J. D. (2013). Applied Mathematics. John Wiley \& Sons, 688.

[2] Hameed, R. A., Arif, G. E., Hamdi, A. A. (2017). Estimatig the amount of potassium radiation effect on soil using Neville and Hermite numerical methods. Tikrit Journal of Pure Science, 22 (9), 100-105.

[3] Velten, H., Montiel, A., Carneiro, S. (2013). GRB Hubble diagram and constraints on a $\Lambda(t)$ CDM model. Monthly Notices of the Royal Astronomical Society, 431 (4), 3301-3306. doi: https://doi.org/10.1093/mnras/stt409

[4] Burden, R. L., Faires, J. D. (2005). Numerical Analysis 8th Edition. Thompson Brooks/Cole.

[5] Richard, L., Burden, J. (2011). Douglas Faires, Numerical Analysis. Brooks/Cole.

[6] Gusev, A., Vinitsky, S., Chuluunbaatar, O., Chuluunbaatar, G., Gerdt, V., Derbov, V. et. al. (2018). Interpolation Hermite Polynomials For Finite Element Method. EPJ Web of Conferences, 173, 03009. doi: https://doi.org/10.1051/epjconf/201817303009

[7] Baker, H. A. A. (2008). Estimation of Surface Dose (Skin Absorbed Dose) for the Patient Undergoing Standards Radiologic Examinations. Journal of Kerbala University, 6 (1), 260-267.

[8] Abdul-Wahid, Sahib Nama, Wissam H Mahdi, Hameed J Hamdan, and Fathel Nama Abdul-Wahid. 2010. "Estimation and Comparison of Diffuse Solar Radiation over Iraq." Kufa Journal of Engineering 1(2): 153-74.

[9] Mahdi, W. H. (2011). Estimation of the Atmospheric CO2 Concentration in Iraq. Journal of Kufa - Physics, 3 (1), 59-67.

[10] Alkadhimi, A. M. H. (2011). Estimation of Land Soil Erosion Using Neural Network Model. Basrah Journal for Engineering Science, 11 (1), 101-114. 
[11] Rogoza, W. (2019). Method for the prediction of time series using small sets of experimental samples. Applied Mathematics and Computation, 355, 108-122. doi: https://doi.org/10.1016/j.amc.2019.02.062

[12] Kadhim, R. M. (2011). Estimation of Entrance Surface Air Kerma (ESAK) and dose area product(DAP) for the patient examined by fluoroscopy apparatus[long term X-ray examination]. Journal of Kerbala University, 9 (1), 189-198.

[13] Al-Kaisi, A. A. R., Ali, H. H. (2013). Mathematical Estimation for the Bearing Capacity of Sand Column Inserted in Soft Clay Soil. Engineering and Technology Journal, 31 (5), 816-827.

[14] Najam, L. A., Majeed, F. A., Kheder, M. H., Younis, S. A. (2017). Estimation the Radiological Hazard Effects for Soil Samples of Nineveh Province. International Journal of Physics, 5 (2), 53-56.

[15] Alsaleem, M. Y. A., Hasoon, S. O. (2020). Comparison of dt\& gbdt algorithms for predictive modeling of currency exchange rates. EUREKA: Physics and Engineering, 1, 56-61. doi: https://doi.org/10.21303/2461-4262.2020.001132

[16] Zaker, N. A., Alsaleem, N., Kashmoola, M. A. (2018). Multi-agent Models Solution to Achieve EMC In Wireless Telecommunication Systems. 2018 1st Annual International Conference on Information and Sciences (AiCIS). doi: https://doi.org/10.1109/ aicis.2018.00061

[17] Alsaleem, N. Y. A., Moskalets, M., Teplytska, S. (2016). The analysis of methods for determining direction of arrival of signals in problems of space-time access. Eastern-European Journal of Enterprise Technologies, 4 (9 (82)), 36-44. doi: https://doi.org/ 10.15587/1729-4061.2016.75716

[18] Kheder, M. H. (2019). Measurement of Radon Concentration Using SSNTD in Bartella Region. Al-Mustansiriyah Journal of Science, 29 (4), 110. doi: https://doi.org/10.23851/mjs.v29i4.357

[19] Agency, Nuclear Energy (1979). Exposure to Radiation from the Natural Radioactivity in Building Materials: Report. OECD. 